Artigo Original

\title{
Instrução verbal: solicitar foco de atenção não garante sua adoção e melhor desempenho
}

\author{
Bettina Ried ${ }^{1,2}$ \\ Meico Fugita ${ }^{2}$ \\ Andrea Michele Freudenheim ${ }^{2}$ \\ Luciano Basso ${ }^{2}$ \\ Umberto César Corrêa ${ }^{2}$ \\ ${ }^{1}$ Escola Superior de Educação Física de Jundiaí; Jundiaí, SP, Brasil \\ ${ }^{2}$ Laboratório de Comportamento Motor, Escola de Educação Física e Esporte, \\ USP - Universidade de São Paulo, SP, Brasil
}

\begin{abstract}
Resumo: Os objetivos deste estudo foram verificar: a) o efeito da instrução com e sem redundância na adoção do foco de atenção externo; b) o efeito do foco de atenção externo no desempenho no nado crawl; e c) o efeito da redundância do enunciado da instrução na adoção do foco e no desempenho. Participaram do estudo 43 universitários de ambos os gêneros com idade entre 17 e 46 anos. A tarefa, nadar 25 m nado crawl em velocidade máxima, foi executada uma vez em cada uma de três condições relativas à instrução: sem foco (SF), com foco (CF) e com foco e redundância (CFR), em ordem contrabalanceada. Como registro de adoção de foco, após a execução o sujeito foi questionado sobre a efetiva adoção do foco de atenção solicitado. Como medida do desempenho, computou-se o índice de braçadas. Os resultados mostraram que nas condições CF e CFR, respectivamente, $23 \%$ e $42 \%$ dos sujeitos não adotaram o foco solicitado; que nas condições CF e CFR a frequência dos sujeitos que adotaram o foco solicitado é superior à dos que não o adotaram, e, na condição $\mathrm{CF}$, em relação à $\mathrm{CFR}$ houve uma frequência superior de sujeitos que adotaram o foco solicitado. $O$ desempenho não diferiu significativamente entre as três condições $(p>0,05)$. Concluiu-se que: a) não basta solicitar que seja adotado um foco de atenção para que este seja de fato adotado; b) não houve efeitos do foco de atenção externo no desempenho; e c) a adoção de uma instrução sem redundância é maior, mas sem reflexos sobre o desempenho.
\end{abstract}

Palavras-chave: Atenção. Desempenho psicomotor. Análise e desempenho de tarefas.

\section{Verbal instruction: \\ requesting an attentional focus does not ensure compliance and better performance}

\begin{abstract}
The purposes of this study were to investigate a) the effect of redundant and non-redundant instruction on external focus of attention adoption, b) the effect of adopting an external focus of attention on performance in a front crawl swimming task, and c) the effect of redundancy in the wording of a verbal instruction on the above variables. 43 college students (m/f) aged 17 to 46 swam $25 \mathrm{~m}$ crawl at maximum speed, once under each of three conditions: without focus instruction (SF), following a focus instruction (CF) and a redundant focus instruction (CFR), in counterbalanced order. For focus adoption control, after completing the task participants were asked about what they had focused on while swimming. As a measure of performance, time and number of strokes were taken and the stroke index was calculated. The results showed that under redundant focus instruction (CFR) condition, $42 \%$ failed to adopt the attentional focus as asked, and following focus (CF) instruction, $23 \%$. Under CF condition, the frequency of participants that adopted the focus was higher than of those who did not. Performance did not differ significantly among the three conditions $(p>0,05)$. These findings stress the need of manipulation checks in attentional focus research, regarding both performance and motor learning efficiency, as well as the need for further investigation into the relation between instruction extension and performance.
\end{abstract}

Keywords: Attention. Psychomotor performance. Task performance and analysis.

\section{Introdução}

Vários pesquisadores têm investigado o efeito do foco de atenção no desempenho e aprendizagem de habilidades motoras. Mais especificamente, tem-se comparado os efeitos do foco de atenção externo com aqueles do foco de atenção interno. $O$ foco interno se refere aos movimentos do corpo e o externo, aos efeitos desse movimento sobre 0 ambiente (WULF, 1998). Estes estudos têm sido desenvolvidos com tarefas variadas como batida do golfe (BEILOCK, 2001; BEILOCK el al., 2002; PERKINS-CECCATO, 2003; BELL, 2009), 
arremesso do dardo de salão (RADLO, 2002; SCHORER, 2008; MARCHANT, 2007), chute e drible do futebol (BEILOCK el al, 2002; FORD el al, 2009), simulador de esqui (WULF; 1998) e natação (FREUDENHEIM, 2010; PASETTO, 2011).

A maior parte dos estudos apresenta evidências do maior benefício do foco de atenção externo em comparação ao interno, tanto em relação ao desempenho quanto para a aprendizagem de habilidades motoras, especialmente em habilidosos (WULF, 2007). Essa superioridade é explicada por a atenção, no foco interno, trazer os processos de controle ao nível consciente, tornando-os assim mais lentos e, em consequência, comprometendo o desempenho (WULF, 2001; BEILOCK el al, 2002). Em uma explicação alternativa, os efeitos benéficos do foco externo resultam da quantidade reduzida de informações a serem processadas nessa condição em comparação com a condição de foco interno (POOLTON, 2007).

Embora seguir a instrução sobre o foco de atenção seja um aspecto crítico (MAXWELL, 2002), poucos são os estudos sobre foco de atenção que apresentam controle da adoção do foco solicitado (BELL, 2009). É possível que fatores como a linguagem utilizada, definida pelo contexto, pelo tema e pelos falantes, dificultem a compreensão e impliquem na não adoção da instrução na realização das tarefas por parte de alguns dos executantes. Assim, se alguma das informações sobre a tarefa não estiver clara através desses elementos definidos pelo contexto, então os executantes precisam ser informados verbalmente.

No caso da natação, por exemplo, diferenças no nível de compreensão dos ouvintes podem levar a diferentes interpretações de uma mesma instrução. Para nadadores habilidosos, a expressão: "empurre a água para trás" tem significado diferenciado em relação a nadadores novatos, pois entendem que com esta ação é possível tracionar o corpo para frente. Para muitos nadadores novatos, no entanto, não há diferença no significado entre "leve a mão para trás" e "empurre a água para trás" em função da menor capacidade de interpretar as percepções da pressão (COLWIN, 2000).
No presente estudo partiu-se do pressuposto de que a redundância da instrução verbal sobre o foco de atenção externo pudesse favorecer não só a compreensão, mas a adoção pelo executante do foco de atenção solicitado. Tendo em vista tais pressupostos, os objetivos do presente estudo foram investigar: a) o efeito da instrução com e sem redundância na adoção do foco de atenção externo; b) o efeito do foco de atenção externo no desempenho no nado crawl; e c) o efeito da redundância do enunciado da instrução na adoção do foco e no desempenho.

\section{Método}

\section{Amostra}

Participaram do estudo 43 universitários de ambos os sexos com idade entre 17 e 46 anos (média 22,9 $\pm 7,2$ anos), que informaram praticar natação esporadicamente (no máximo duas vezes por mês) e assinaram termo de consentimento livre e esclarecido aprovado pelo Comitê de Ética em Pesquisa da Escola Superior de Educação Física de Jundiaí, em 12 de setembro de 2008, sob o número do processo 012/08 - CAAE 0011.0.335.000-8.

\section{Material}

A coleta de dados foi realizada em uma piscina coberta e aquecida $\left(29^{\circ} \mathrm{C}\right)$, com comprimento de $25 \mathrm{~m}$ e profundidade entre 0,90 e $3,50 \mathrm{~m}$. Para o registro do tempo foram utilizados dois cronômetros marca CLA 1063 AG13x1. A contagem e o registro do número de braçadas foram realizados por dois auxiliares durante a execução da tarefa pelo participante.

\section{Tarefa e delineamento experimental}

A tarefa consistiu em nadar $25 \mathrm{~m}$ utilizando o nado crawl, em velocidade máxima, saindo de dentro da água, com impulsão da borda, sem deslize prolongado nem movimentos ondulatórios do tronco ("golfinhadas").

Cada participante executou a tarefa três vezes, sendo uma tentativa em cada uma das três condições: instrução sem foco (SF), com foco de atenção (CF) e com foco de atenção e redundância (CFR), em sequência contrabalanceada entre os sujeitos. Após completar 0 percurso, 0 voluntário era questionado sobre o foco de atenção adotado durante a execução da tarefa. Logo após, houve um intervalo de três minutos para descanso e preparação da próxima tentativa, durante o qual - voluntário permanecia na água em movimentação leve. Não foi realizado treino 
prévio na tarefa, seguindo procedimento adotado pelos estudos anteriores relativos ao foco de atenção (WULF, 1998 e CASTANEDA, 2007).

\section{Procedimentos}

O voluntário recebeu a instrução verbal sobre a tarefa de acordo com as condições específicas antes de realizar cada tentativa. Os trechos entre parênteses eram incluídos quando a respectiva instrução era fornecida em uma tentativa que não fosse a primeira. Os trechos em caixa alta eram pronunciados com destaque.

(a) Instrução sem foco (SF): "Você vai (mais uma vez) nadar em velocidade MÁXIMA, (como nas tentativas anteriores), e (lembre-se) sem deslize prolongado, nem golfinhadas".

(b) Instrução com foco de atenção (CF): "Vamos focalizar a atenção num (outro) aspecto do nado (diferente da tentativa anterior). Você vai (mais uma vez) nadar em velocidade MÁXIMA, (como nas tentativas anteriores), e (lembre-se) sem deslize prolongado nem golfinhadas. Só que (agora) é importante que focalize sua atenção num (outro) aspecto: durante a fase AQUÁTICA da braçada, você deve concentrar-se em empurrar a ÁGUA para trás. É MUITO IMPORTANTE que você focalize na ÁGUA enquanto ela vai sendo EMPURRADA para trás."

(c) Instrução com foco de atenção e redundância (CFR): "Vamos focalizar a atenção num (outro) aspecto do nado (diferente da tentativa anterior). Você vai (mais uma vez) nadar na velocidade MÁXIMA, (como nas tentativas anteriores), e (lembre-se) sem deslize prolongado nem golfinhadas. Só que (agora) é importante que focalize sua atenção num (outro) aspecto: durante a fase AQUÁTICA da braçada, você deve concentrar-se em empurrar a ÁGUA para trás. É MUITO IMPORTANTE que você focalize na ÁGUA enquanto ela vai sendo EMPURRADA para trás, BUSCANDO O MELHOR APOIO. É MUITO IMPORTANTE que você focalize na ÁGUA enquanto ela vai sendo EMPURRADA para trás COM O MELHOR APOIO".

As instruções com foco foram elaboradas de acordo com as diretrizes postuladas pela teoria da comunicação verbal (MARCUSCHI,1998; BRANSFORD, 2002; TIELEMANN, 2008). Iniciam-se com uma frase introdutória para caracterizar $\mathrm{o}$ assunto da mensagem e assim sintonizar o referencial. $\mathrm{Na}$ segunda frase, descrevem o comportamento esperado: "nadar em velocidade máxima". Para as condições $\mathrm{CF}$ e CFR, a terceira frase introduz o assunto da mensagem seguinte: que a atenção deveria ser focalizada em um determinado detalhe durante $o$ nado. Somente a quarta frase especifica o foco a ser adotado durante o percurso.

No caso do grupo CFR, introduz-se redundância no enunciado e assim possivelmente diminui-se a incerteza do receptor sobre o conteúdo da mensagem: às quatro frases foi adicionada uma quinta, que repetiu a mensagem da quarta frase com palavras de significado ligeiramente diferentes, e acrescida mais uma informação sobre 0 efeito do movimento no ambiente.

Como controle da manipulação experimental, ou seja, da efetiva adoção (ou não) do foco de atenção solicitado, após concluir a tentativa correspondente a cada uma das condições, ao participante foi feita a pergunta: "Ao nadar, você prestou atenção naquilo que eu te pedi? Em que foi que você prestou atenção?" e a resposta registrada.

\section{Variáveis dependentes e análise dos dados}

A medida considerada para adoção do foco de atenção foi a frequência de participantes que declararam ter adotado o foco solicitado, em cada uma das condições de instrução, baseado nas respostas dadas às questões. Como medida de desempenho foi utilizado o índice de braçadas, uma medida que avalia a eficiência do nado e que equivale ao produto entre a velocidade do nado e o comprimento da braçada (IB $\left.=v^{*} \mathrm{cb}\right)$; sendo portanto o índice de braçada igual ao produto de velocidade (v) pelo comprimento da braçada (cb). Para calcular o índice de braçadas foi cronometrado o tempo entre a saída dentro da água (o momento em que os pés deixavam a parede da piscina) e a chegada, e contado o número de braçadas (SMITH, 2002). Para verificar diferenças entre as condições, os dados relativos ao desempenho foram submetidos a análise inferencial por meio do teste de análise de variância (ANOVA) oneway para medidas repetidas. Todos os testes foram realizados no SPSS 17.0.

\section{Resultados}

\section{Adoção do foco de atenção}

Os resultados referentes à adoção de foco de atenção podem ser observados na Tabela 1. Pode-se verificar que, nas condições CFR e CF, respectivamente, $42 \%$ e $23 \%$ dos sujeitos não 
adotaram o foco solicitado. $O$ foco de atenção não foi adotado por todos os participantes aos quais foi solicitado.

Tabela 1. Número e porcentagem (\%) de participantes que adotaram e não adotaram o foco de atenção solicitado nas condições de instrução com foco de atenção (CF) e instrução com foco de atenção e redundância (CFR).

\begin{tabular}{lcc}
\hline Condição & Instrução CF & Instrução CFR \\
\hline Adoção & $33(77 \%)$ & $25(58 \%)$ \\
$\begin{array}{l}\text { Não } \\
\text { adoção }\end{array}$ & $10(23 \%)$ & $18(42 \%)$ \\
Total & 43 & 43 \\
\hline
\end{tabular}

\section{Desempenho}

Na Figura 1 são apresentadas as médias e os desvios-padrão do desempenho, em cada uma das três condições. Na condição controle, a média do índice de braçadas foi de 1,1667 (DP = $0,46)$, na condição CFR $1,1536(\mathrm{DP}=0,46)$ e na $\mathrm{CF}, 1,1364(\mathrm{DP}=0,46)$. Os resultados da análise estatística indicaram não haver diferença significativa no desempenho entre as condições $(p>0,05)$.

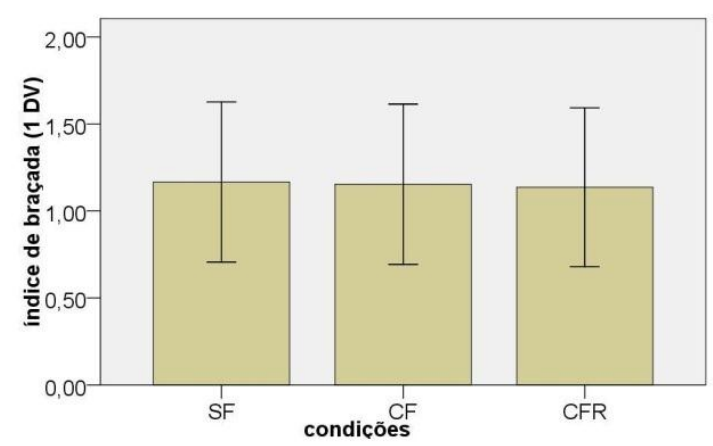

Figura 1. Média e desvio-padrão dos índices de braçadas nas condições de instrução sem foco de atenção (SF), com foco de atenção (CF) e instrução com foco de atenção e redundância (CFR), de todos os sujeitos da amostra.

Para verificar se a semelhança entre os grupos no desempenho se deu em razão da não adoção do foco, analisou-se o desempenho apenas dos participantes que adotaram corretamente o foco atencional solicitado. A Figura 2 mostra 0 desempenho somente daqueles participantes que confirmaram ter adotado o foco solicitado em todas as condições $(n=15)$. O resultado do desempenho é semelhante àquele revelado pela totalidade da amostra: as médias do desempenho nas diferentes condições estão muito semelhantes. $\mathrm{Na}$ condição controle (SF), a média do índice de braçadas foi de 1,1973 ( $\mathrm{DP}=0,41$ ), na condição CF, 1,1307 (DP $=0,45)$ e na CFR 1,1673 (DP = $0,45)$. Os resultados da Anova confirmam os resultados descritivos, em que não há diferenças no desempenho entre os grupos.

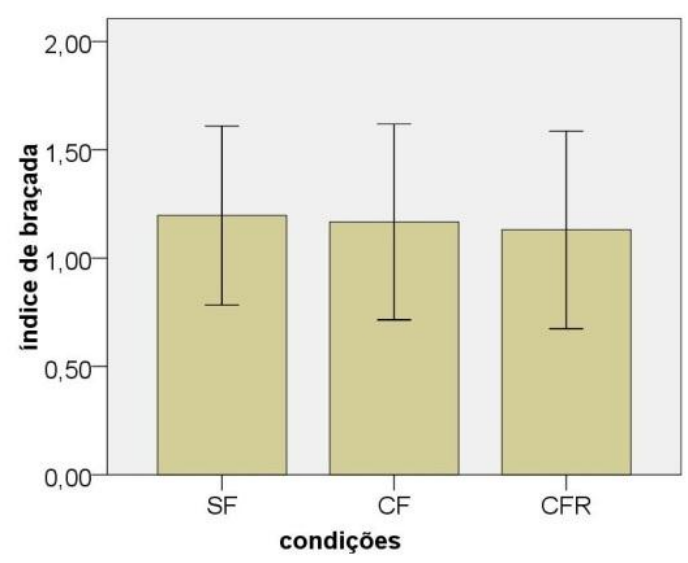

Figura 2. Média e desvio-padrão dos índices de braçadas nas condições de instrução sem foco de atenção (SF), com foco de atenção (CF) e instrução com foco de atenção e redundância (CFR), apenas dos sujeitos que adotaram o foco de atenção solicitado em todas as condições.

\section{Discussão}

Os objetivos deste estudo foram verificar a) o efeito da instrução com e sem redundância na adoção do foco de atenção externo; b) o efeito do foco de atenção externo no desempenho no nado crawl; e c) o efeito da redundância do enunciado da instrução na adoção do foco e no desempenho.

\section{Sobre a adoção do foco de atenção}

Os resultados mostram que o foco de atenção solicitado nem sempre é adotado pelos sujeitos na execução da tarefa. Os participantes deixaram de adotá-lo nas condições CFR e CF, respectivamente, em $42 \%$ e $23 \%$ dos casos. Tais resultados, embora possam parecer um paradoxo para quem espera uma frequência de adesão ao foco de atenção próxima de $100 \%$, apontam na mesma direção do resultado de Ford (2009) em que $25 \%$ dos novatos não aderiram ao foco solicitado. Portanto, não basta solicitar a executantes novatos em uma habilidade motora que adotem um determinado foco de atenção para que tal foco seja de fato adotado. Estes resultados reforçam a necessidade de incluir instrumentos de controle da adoção do foco em pesquisas relativas à eficiência do foco de atenção, principalmente, em se tratando de executantes novatos, procedimento não reportado pela grande maioria dos estudos na área (BELL, 2009). 
Nesse sentido, o resultado desse estudo não surpreende. Poolton (2007) argumentam que o foco externo leva a desempenho melhor devido à menor demanda atencional no processamento da informação proveniente do meio externo, enquanto na condição de foco interno a quantidade de informação a ser processada é maior e com isso a demanda atencional também. No presente estudo, a diferença na frequência de adoção do foco pode ser atribuída à diferença na quantidade de informação a ser processada, entre a instrução com redundância e aquela sem redundância. Nesse caso, a instrução com redundância, por compreender maior quantidade de informação, teria um efeito similar ao da instrução de foco interno (POOLTON el al, 2007), ou seja, comprometer, no nosso caso, a adoção do foco .

Por outro lado, fica aberta a questão "até que ponto as informações redundantes de fato são processadas separadamente, aumentando a demanda atencional". Guadagnoli (2004) propõem que a quantidade de informação transmitida depende do grau de redução de incerteza que se consegue com a informação. Nesse sentido, quando na percepção do participante a incerteza é pequena, pouca informação é transmitida e consequentemente a chance de a solicitação de adotar um foco de atenção ser seguida é menor. Esse raciocínio corresponde com o de Colwin (2000) com relação à limitação na compreensão por parte dos nadadores novatos. Especificamente, na falta de referencial perceptivo, uma instrução redundante pode comprometer ainda mais esta compreensão devido à maior quantidade de informações que talvez não possam ser interpretadas, levando à não adoção do foco. Desta forma, a grande quantidade de informação, que não reduz a incerteza, não ajuda na compreensão, mas, ao contrário, compromete. Assim, para contornar essa situação, além de controlar a adoção do foco, talvez seja importante mostrar a relevância dessa adoção ao executante e de familiarizá-lo com cada uma das condições antes de solicitálas. Em estudos futuros essa questão deverá ser considerada.

\section{Sobre os efeitos do foco de atenção externo no desempenho no nado crawl}

Analisando-se os resultados referentes somente aos participantes que adotaram o foco solicitado, em relação ao desempenho, não foi detectada diferença entre as condições controle (SF) e com foco de atenção (CF e CFR) no nado crawl dos participantes. Esse resultado não corrobora as evidências do maior benefício do foco de atenção externo em comparação à condição sem foco, no desempenho de habilidades motoras (WULF, 2007, MARCHANT el al, 2009; FORD el al, 2009). Está, no entanto, de acordo com os estudos de De Paul el al, (2009), Marchant el al (2007) e Ford el al (2009), nos quais o desempenho nas condições instrução com foco externo e sem foco foi igual, em se tratando de participantes novatos.

Uma possível explicação para a ausência de diferença no desempenho entre instrução com foco externo e sem foco pode ser o alto grau de dificuldade funcional, proposto por Guadagnoli (2004). Em específico, participantes novatos solicitados a executar uma tarefa complexa podem não estar preparados para processar uma informação adicional relativa a essa tarefa. Conforme mostraram Guadagnoli (2004), o tipo de informação passível de ser processado varia com o nível de habilidade. Em novatos, a demanda de recursos atencionais relativa à instrução de foco compete com a demanda relativa à execução do movimento. Assim, a instrução com foco, seja com ou sem redundância, possivelmente excede o limite de recursos atencionais disponíveis nos novatos.

Todos os participantes foram instruídos a nadar em velocidade máxima. $O$ fator que diferenciou as condições foi a solicitação (ou não) de adoção do foco de atenção. Assim, devido à dificuldade em lidar com a demanda adicional (CASTANEDA, 2007), os participantes podem ter estabelecido como foco principal nadar em velocidade máxima, anulando assim a diferença entre as condições experimentais. Assim, mesmo tendo adotado o foco solicitado, não conseguiram usá-lo para realizar movimentos mais eficientes e, em conseqüência, apresentar desempenhos diferenciados em relação à condição SF. Em diversos estudos (DE PAUL el al, 2009; FORD el al, 2009; MARCHANT el al, 2007), a igualdade entre condição sem foco e condição foco externo bem como a diferença entre as duas condições e a condição de foco interno foi explicada pela demanda atencional, ou seja, as informações contidas na instrução excediam a capacidade de processamento dos novatos. Do mesmo modo, no presente estudo, uma possível explicação para os resultados obtidos é que, na condição de foco externo, a quantidade de informação extrapolou a capacidade atencional do novato, comprometendo a adoção do foco. Portanto, no caso de nadadores novatos, atentar para o foco específico não foi suficiente para favorecer a eficiência na execução do movimento e consequente melhora do desempenho. 
Sobre o efeito da redundância do enunciado da instrução na adoção do foco

\section{e no desempenho}

O resultado desse estudo contraria a predição de que uma mensagem redundante favoreceria a compreensão (MARCUSCHI, 1998; BRANSFORD; 2002; TIELEMANN, 2008) necessária a um desempenho com êxito da tarefa. A redundância presente na instrução CFR, ao invés de auxiliar na adoção do foco, parece não ter oferecido possibilidade de melhora no desempenho dos participantes por sobrecarregar os mecanismos de atenção do sujeito, conforme já mostramos. Essa sobrecarga pode ter sido especialmente aumentada pelo fato de tratar-se de sujeitos novatos.

Seria precipitado, no entanto, generalizar os resultados e afirmar que quanto menor a redundância, maior a frequência de adoção do foco. Em futuros estudos talvez a comparação entre sujeitos mais habilidosos e menos habilidosos permita verificar possíveis diferenças decorrentes do nível de habilidade na frequência de adoção em função da redundância do enunciado da instrução. Vale lembrar-se da predominância de desempenho superior na condição de foco externo, em relação à sem foco e à de foco interno, em sujeitos habilidosos na literatura (WULF, 2007). Outro fator limitador do estudo pode ter sido a distância de $25 \mathrm{~m}$, eventualmente insuficiente para evidenciar influências discretas do foco de atenção, embora os estudos de Pasetto el al (2011) e Freudenheim el al (2010) tenham utilizado distância ainda menor (16 m), obtendo resultados divergentes. $\mathrm{O}$ fato de a resposta ser dada pelos voluntários oralmente pode tê-los levado a se sentirem na obrigação de afirmar que tinham prestado atenção no foco indicado. Estudos futuros poderão optar por adotar outras formas de controlar a adoção do foco pelos sujeitos, como por exemplo, a resposta por escrito ou anônima.

Ainda, a diferença na frequência de adoção de foco não está associada a uma diferença no desempenho entre as condições CF e CFR. Este resultado reforça o argumento anterior de que, em função do alto grau de dificuldade funcional, solicitar a adoção de foco específico pode não ser suficiente para favorecer a eficiência na execução do movimento e, por conseguinte, o desempenho.

Em síntese, pode-se concluir que, em relação a participantes menos habilidosos, na tarefa de nadar crawl em velocidade máxima: a) não basta solicitar que nadadores adotem um determinado foco de atenção para que tal foco seja de fato adotado; b) não houve efeitos do foco de atenção externo no desempenho; c) quando comparado a uma instrução com redundância no enunciado, há maior adoção de uma instrução sem redundância, mas essa não se expressa no desempenho; e, d) o conjunto de resultados permite concluir que, quando há alta dificuldade funcional, atentar para o foco específico, mesmo que externo, pode não ser suficiente para favorecer a eficiência na execução do movimento e, por conseguinte, o desempenho.

\section{Referências}

BEILOCK, S.L.; CARR, T.H. On the fragility of skilled performance: what governs choking under pressure? Journal of Experimental Psychology General, Washington, v. 130 , n. 4, p. 701-725, 2001.

BEILOCK, S. L.; CARR, T. H.; MCMAHON, C.; STARKES, J. L. . When paying attention becomes counterproductive: Impact of divided versus skill-focused attention on novice and experienced performance of sensorimotor skills. Journal of Experimental Psychology: Applied, Washington, v. 8, n.1, p.6-16, 2002.

BELL, J.; HARDY, J. Effects of Attentional Focus on Skilled Performance in Golf. Journal of applied Sport Psychology, London, v. 21, n. 2, p. 163-177, 2009.

BRANSFORD, J. D.; JOHNSON, M. Contextual prerequisites for understanding: Some investigations of comprehension and recall. In: BALOTA, David \& MARSH, Elizabeth. Cognitive Psychology, New York, Psychology Press, p. 431 - 439, 2002.

CASTANEDA, B.; GRAY, R. Effects of Focus of Attention on Baseball Batting Performance in Players of Differing Skill Levels. Journal of Sport \& Exercise Psychology, Champaign, v. 29, p. 60-77, 2007.

\section{COLWIN, C.M. Nadando para o século XXI.} São Paulo, Manole, 2000.

DE PAUL, V.; WISHART, I.; LEE, T. Impact of focus of attention instructions on walking performance in individuals with and without history of stroke. 2009 NASPSPA Conference Abstracts, Journal of Sport \& Exercise Psychology, Champaign, v. 31 (supplement), p. 60, 2009.

FORD, P.; HODGES, N., HUYS, R.; WILLIAMS, A. An Evaluation of End-Point Trajectory Planning During Skilled Kicking. Motor Control, Champaign, v. 13, p. 1, 2009. 
FREUDENHEIM, A. M.; WULF, G.; MADUREIRA, F.; CORRÊA, U. C.; PASETTO, S.C. . An external focus of attention results in greater swimming speed. International Journal of Sports Science \& Coaching, Brentwood, v. 5, p. 533-542, 2010.

GUADAGNOLI, M.A.; LEE, T.D. Challenge point: a framework for conceptualizing the effects of various practice conditions in motor learning. Journal of Motor Behavior, Washington, v. 36, n. 2, p.221-224, 2004.

MARCHANT, D.; CLOUGH, P.; CRAWSHAW, M. The Effects of attentional focusing strategies on novice dart throwing performance and their task experiences. International Journal of Sport \& Exercise Psychology, Aachen, v. 5, n. 3, p. 291303, 2007.

MARCHANT, D.C.; GREIG, M.; SCOTT, C. Attentional focusing instructions influence force production and muscular activity during isokinetic elbow flexions. Journal of Strenght and Conditioning Research, Philadelphia, v. 23, n. 8, p. 2358-2366, 2009.

MARCUSCHI, L. A. Atividades de compreensão na interação verbal. In: PRETI, Dino (org.).

Estudos de Língua Falada: variações e confrontos. São Paulo, Humanitas/FFLCH/USP, p. $15-46,1998$.

MAXWELL, J.P.; MASTERS, R.S.W. External versus internal focus instructions: Is the learner paying attention? International Journal of Applied Sports Sciences, Seoul, v. 14, p. 70-88, 2002.

PASETTO, S.C.; RIED, B. U. W.; FREUDENHEIM, A. M.; CORRÊA, U. C. Efeitos do foco de atenção no desempenho do nado Crawl: componentes posição do corpo e respiração. Brazilian Journal of Motor Behavior, São Paulo, v. 6, p. 31-36, 2011.

PERKINS-CECCATO, N.; PASSMORE, S.; LEE, $T$. Effects of focus of attention depend on golfer's skill. Journal of Sports Sciences, London, v. 21, p. 593-600, 2003.

POOLTON, J.M.; MAXWELL, J.P.; MASTERS, R.S.W.; VAN DER KAMP, J. Moving with an external focus: Automatic or Simply Less Demanding? E-Journal Bewegung und Training, Hamburg, v. 1, p. 43-44 2007.

RADLO, S.; STEINBERG, G.; SINGER, R.; BARBA, D; MELNIKOV, A. The Influence of an attentional Focus Strategy on Alpha Brain Wave Activity, Heart Rate, and Dart-Throwing Performance. International Journal of Sport \& Exercise Psychology, Aachen, v. 33, p. 205217, 2002.
SCHORER, J.; WOLLNY, R.

Aufmerksamkeitsfokussierungen beim

Dartwerfen. Disponível em:

$<$ http://www.schorer.eu/vortraege en.html $>$.

Acesso em: 09 nov. 2008.

SMITH, D.; NORRIS, S.; HOGG, J. Performance Evaluation of Swimmers. Sports Medicine, Auckland, v. 32, n. 9, p. 539-554, 2002.

TIELEMANN, N.; RAAB, M.; ARNOLD, A. Effekte von Instruktionen auf motorische Lernprozesse.

Zeitschrift fuer Sportpsychologie, Köln, v. 15, n. 4 , p. $118-128,2008$.

WULF, G. Attention and Motor Skill Learning. Champaign, Human Kinetics, 2007.

WULF, G., HOESS, M.; PRINZ, W. Instructions for Motor Learning: diferential effects of internal versus external focus of attention. Journal of Motor Behavior, Washington, v. 30, p. 169-179, 1998.

WULF, G.; McNEVIN, N.; SHEA, C. The automaticity of complex motor skill learning as a funciton of attentional focus. The Quarterly Journal of Experimental Psychology, Hove, $v$. 54 A, n.4, p. 1143-1154, 2001.

Agradecimento: Escola Superior de Educação Física de Jundiaí pelo apoio na coleta de dados.

Endereço:

Bettina Ried

R. Rodrigues de Oliveira, s/n Anhangabaú Jundiaí SP Brasil

13208-120

Telefone/Fax: $+55114521-7955$

e-mails: bettina.ried@gmx.net; amfreud@usp.br

Recebido em: 7 de novembro de 2010.

Aceito em: 25 de março de 2012.

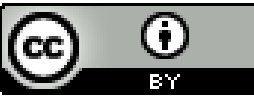

Motriz. Revista de Educação Física. UNESP, Rio Claro, SP, Brasil - elSSN: 1980-6574 - está licenciada sob Creative Commons - Atribuição 3.0 